\title{
Novel Coronavirus 2019 (2019-nCoV) Infection: Part I - Preparedness and Management in the Pediatric Intensive Care Unit in Resource-limited Settings
}

\author{
Namita Ravikumar ${ }^{1}$, Karthi Nallasamy ${ }^{1}$, Arun Bansal ${ }^{1}$, SUResh Kumar Angurana ${ }^{1}$, Basavaraja GV $^{2}$, Manu

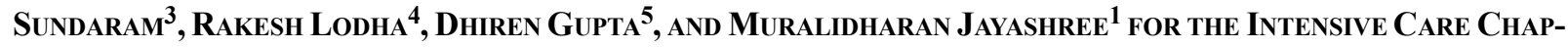 \\ TER OF INdian ACADEMy OF PEDiatrics \\ From Division of Pediatric Critical Care, Departments of Paediatrics, ${ }^{1}$ Advanced Paediatrics Centre, Postgraduate Institute of \\ Medical Education and Research (PGIMER), Chandigarh, India; ${ }^{2}$ Paediatric Intensive Care Unit, Indira Gandhi Institute of Child \\ Health, Bangalore Karnataka, India; ${ }^{3}$ Division of Critical Care Medicine, Sidra Medicine, Doha, Qatar; ${ }^{4}$ Department of \\ Pediatrics, All India Institute of Medical Sciences, New Delhi, India; and 5 Pediatric Intensive Care Unit, Sir Ganga Ram Hospital, \\ New Delhi, India. \\ Correspondence to:Dr Arun Bansal, Professor, Department of Pediatrics, Advanced Pediatrics Centre, Postgraduate Institute of \\ Medical Education and Research, Chandigarh,India.drarunbansal@gmail.com \\ Received: March 26, 2020; Initial review: March 28, 2020; Accepted: March 31, 2020.
}

First reported in China, the 2019 novel coronavirus has been spreading across the globe. Till 26 March, 2020, 416,686 cases have been diagnosed and 18,589 have died the world over. The coronavirus disease mainly starts with a respiratory illness and about $5-16 \%$ require intensive care management for acute respiratory distress syndrome (ARDS) and multi-organ dysfunction. Children account for about $1-2 \%$ of the total cases, and $6 \%$ of these fall under severe or critical category requiring pediatric intensive care unit (PICU) care. Diagnosis involves a combination of clinical and epidemiological features with laboratory confirmation. Preparedness strategies for managing this pandemic are the need of the hour, and involve setting up cohort ICUs with isolation rooms. Re-allocation of resources in managing this crisis involves careful planning, halting elective surgeries and training of healthcare workers. Strict adherence to infection control like personal protective equipment and disinfection is the key to contain the disease transmission. Although many therapies have been tried in various regions, there is a lack of strong evidence to recommend anti-virals or immunomodulatory drugs.

Keywords: COVID-19, Guideline, Pandemic, SARI, Treatment.

Published online: March 29, 2020; PII: S097475591600151

$\mathrm{T}$ he year 2020 started with the emergence of the 2019 novel corona virus $(2019-\mathrm{nCoV})$ as a threat to the world; shortly afterwards the World Health Organization (WHO) declared it a pandemic. Having begun in China, globalization and travel led its spread all over the globe, overwhelming the healthcare resources and resulting in high mortality and morbidity. About $5 \%$ of adults, especially those with comorbidities, were critically ill and required intensive care unit (ICU) care [1]. People of all ages were found to be susceptible but severe illness was rare in children [2]. Most of the experience of critical care management of pediatric patients with coronavirus disease 2019 (COVID-19) is derived from the affected children of present epidemic in China, as well as from the previous coronaviral outbreaks viz. Severe acute respiratory syndrome (SARS) and Middle East respiratory syndrome (MERS). We write this review as a guidance statement for preparedness and managing children with suspected or confirmed COVID-19 requiring intensive care in a resource-limited setting like India.

\section{BURDEN}

Global: Till March 26, 2020, a total of 416,686 confirmed cases from 197 countries with 18,589 deaths have been reported by WHO. China has reported the maximum cases with a total of 81,869 , followed by Italy with 69,176 cases. However, mortality is more in Italy with $6,820(9.9 \%)$ deaths followed by China having 3,287 (4\%) deaths. The United States of America has surpassed Spain and Germany over the last few days with 51,914 cases and 673 deaths [3].

Indian scenario: A total of 606 cases with 10 deaths have been reported from India as on March 26, 2020 as reported by the WHO. Among these cases, only one child from Kerala has been tested positive.

\section{EPIDEMIOLOGY}

The 2019-nCoV belongs to a group of enveloped positive-sense RNA viruses in the family, Coronaviridae with 4 genera viz., alpha, beta, gamma and delta. Human coronaviruses $(\mathrm{HCoV})$ belong to alpha and beta genus 
and are mostly implicated in endemic respiratory infection with mild severity [4]. However, the novel coronaviruses infecting humans namely, SARS-CoV, MERS-CoV and SARS-CoV-2 are believed to have originated from bats with few intermediate hosts like civet cats, camels and pangolins [5]. RNA viruses mutate faster than DNA viruses, single-stranded viruses mutate faster than double-strand virus, and genome size appears to correlate negatively with mutation rate.

\section{Transmission Characteristics}

It is speculated that it originated in bat (genetic character matches to bat corona virus) then it got transmitted to pangolins, or scaly anteaters. Humans seem to be accidental host who got this virus from pangolins in Wuhan seafood market. Human to human transmission of COVID-19 started in Wuhan city, Hubei Province of China where it was initially labelled as 'Pneumonia of unknown etiology'. Epidemiological investigation of early transmission dynamics revealed that $55 \%$ of the cases of COVID-19 during December, 2019 were linked to the hunan seafood wholesale market. The mean incubation period has been reported to be 5.2 days with the $95^{\text {th }}$ centile being 12.5 days. The main modes of transmission include droplet and fomites followed by airborne transmission. Reproduction number of nCoV-19 is between 2.2 to 3.6, which is comparable to SARS-CoV but higher than MERS-CoV[6].

Less severe affection in children: Children less than 10 years of age accounted for $1 \%$ of the total cases [1]. The median age among pediatric cases was 6.7 years [7]. The lesser proportion of severe cases among children has been attributed to lesser opportunities for exposure and immaturity of angiotensin converting enzyme 2 receptors, which are proposed to be the binding sites for coronaviruses $[8,9]$.

\section{Case Fatality Rate}

The overall case fatality rate as per China Centre for Disease Control and Prevention (CDC) is 2.3\%, which is much lower compared to SARS (9.6\%) and MERS (34\%) but significantly higher compared to the latest H1N1 influenza pandemic $(0.001-0.007 \%)[1]$. However, as per $\mathrm{WHO}$, the global case fatality rate is as high as $4.4 \%$ with absolute number of deaths already higher than the total fatality of SARS and MERS combined [10]. The case fatality reported from Italy is $7.2 \%$ which has gone up to $9.8 \%$ as per WHO (as on March 26, 2020) [11].

\section{CLINICAL MANIFESTATIONS}

The common clinical features reported in the critically ill patients include fever (98\%), cough (77\%), dyspnea
(63\%), malaise (35\%), myalgia, headache, nausea, vomiting and diarrhea [12]. A prospective study from China involving 171 children with confirmed COVID-19 reported fever $(41 \%)$ with a median duration of 3 days (116 ), cough (48\%), pharyngeal erythema (46\%) tachypnea (28\%) and diarrhea (8.8\%). The cohort had 15\% asymptomatic, $19 \%$ upper respiratory infection, and $65 \%$ pneumonia. Only 3 children (1.7\%) required care and mechanical ventilation. All three of them had comorbidities, and one died [7].

\section{ICU Requirements in COVID}

The severe and critical categories require admission and management in ICU. Among adults, 7\% of patients admitted with SARS-CoV-2 pneumonia required ICU care. The mean age of these ICU patients was 60 years with male: female ratio of $2: 1$ and $50 \%$ had chronic illness. Majority had Multi-organ dysfunction syndrome (MODS) with ARDS (67\%), acute kidney injury (29\%), liver dysfunction (29\%) and cardiac injury (23\%). Of the ICU admissions, $71 \%$ required mechanical ventilation, $35 \%$ vasoactive support, $17 \%$ renal replacement therapy and $11 \%$ ECMO. Mortality was as high as $61 \%$ among the critically ill [12]. As per unpublished data from Italy, $16 \%$ of admitted patients with COVID-19 needed ICU care [13]. In the Chinese pediatric cases, $5.9 \%$ of all pediatric cases belonged to the severe or critical categories. Based on the experience in managing community-acquired pneumonia, high-risk pediatric population includes children with underlying conditions such as congenital heart disease, broncho-pulmonary hypoplasia, airway/lung anomalies, severe malnutrition, and immunocompromised state; however, more information is needed in the setting of COVID-19 [2].

\section{DIAGNOSIS}

Case definitions for suspected, probable and confirmed COVID-19 cases as given by WHO are in Box I [16]. The largest series on children analyzing suspected and confirmed COVID cases is from the electronic data base of Chinese CDC [17]. Cases were suspected based on the presence of clinical features and exposure history. They also identified high-risk cases and categorized into groups based on severity (Box II).

Laboratory testing of suspected cases is based on clinical and epidemiological factors. Screening protocol should be adapted to local situation and may change with the evolution of the outbreak scenario in the local population. Recent testing strategy in India (as on March 20, 2020) given by ICMR is as per algorithm in Fig. 1[18]. Specimen handling for molecular testing would require Biosafety 2 (BSL-2) or equivalent facilities. 


\section{BOX I World Health Organization Case Definitions for Coronavirus Disease 19 (COVID-19)}

\section{Suspect case}

A. A patient with acute respiratory illness (fever and at least one sign/symptom of respiratory disease (e.g., cough, shortness of breath), AND with no other etiology that fully explains the clinical presentation AND a history of travel to or residence in a country/area or territory reporting local transmission (See situation report) of COVID-19 disease during the 14 days prior to symptom onset.

OR

B. A patient with any acute respiratory illness AND having been in contact with a confirmed or probable COVID19 case (see definition of contact) in the last 14 days prior to onset of symptoms

OR

C. A patient with severe acute respiratory infection (fever and at least one sign/symptom of respiratory disease (e.g., cough, shortness breath) AND requiring hospitalization AND with no other etiology that fully explains the clinical presentation.

Probable case

A suspect case for whom testing for COVID-19 is inconclusive. Inconclusive being the result of the test reported by the laboratory

Confirmed case

A person with laboratory confirmation of COVID-19 infection, irrespective of clinical signs and symptoms

Source: World Health Organization [16].

BOX II Risk Stratification and Severity Categorization for Coronavirus Disease-19 (COVID-19)

High risk cases

Clinical features

Laboratory tests

Radiology

Severity categorization

Asymptomatic infection

Mild

Moderate

Severe

Critical
Fever, respiratory/ digestive symptoms, fatigue

Leukopenia, lymphopenia, high C-reactive protein

Abnormal chest ray

No clinical or radiological features but tested positive

Upper respiratory or gastrointestinal symptoms and signs

Clinical/radiological features of lower respiratory involvement

Presence of dyspnea or hypoxemia requiring oxygen, refusal to feed, altered sensorium

Organ dysfunction including Acute respiratory distress syndrome (ARDS), shock, encephalopathy, myocardial dysfunction, coagulation dysfunction and acute kidney injury

Modified From Dong, et al. [17].

Attempts to culture the virus require minimum of BSL-3 facilities [19].

\section{Type of Sample}

Upper respiratory specimens: nasopharyngeal and oropharyngeal swabs; both swabs are placed together in a viral transport medium and transported to the laboratory in ice.

Lower respiratory specimens: sputum and/or endotracheal aspirate or bronchoalveolar lavage in patients with more severe respiratory disease (obtained with aerosol precautions)

\section{Confirmatory Tests}

(a) Respiratory tract or blood samples tested positive for 2019-nCoV nucleic acid using Real-time Reverse Transcriptase - Polymerase Chain Reaction (RT-PCR)

(b) Genetic sequencing of respiratory tract or blood samples is highly homologous with the known 2019$\mathrm{nCoV}$, but this is not done routinely.

Serological tests may help in epidemiological investigation but there could be cross reactivity with other coronaviruses. Viral isolation is not done routinely for diagnosis. Rapid diagnostic test kits like Xpert Xpress 


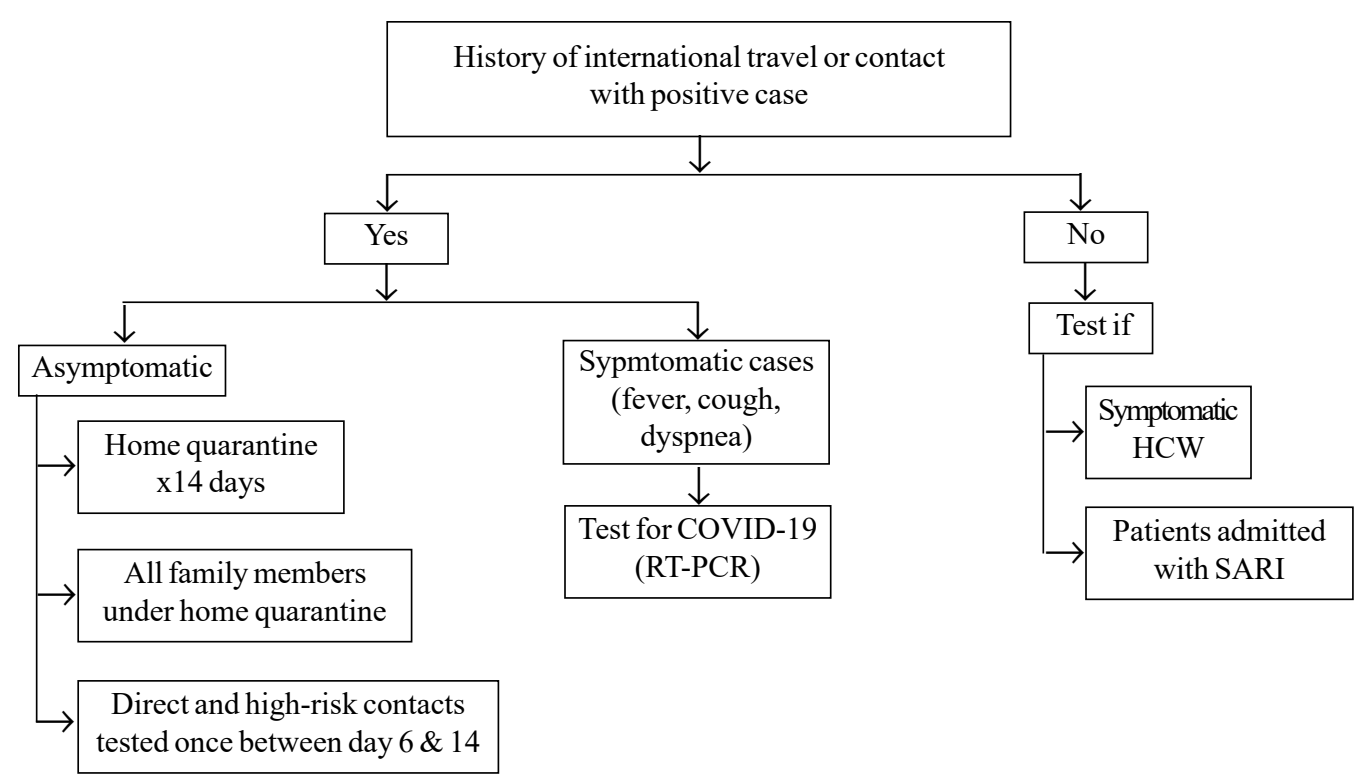

Fig. 1 Testing strategy for suspected cases as per Indian Council of Medical Research.

SARS-CoV-2 by Cepheid has been approved by the USFDA (United States Food and Drug Administration) for Emergency Use Authorization (EUA) and RealStar SARS-CoV-2 RT-PCR kit 1.0 by Altona Diagnostics and Patho Detect by MY LAB have been approved by ICMR[20,21].

\section{Ancillary Investigations}

Complete blood count: Lymphopenia was seen in $85 \%$ of critically ill adults, suggesting it a marker of severe disease while among the overall pediatric cases, it was seen in $3.5 \%[7,12]$.

Infection markers: Elevation of C-reactive protein (CRP) was reported in $20 \%$ and procalcitonin in $64 \%$ of cases [7].

Radiological findings: Chest radiography (CXR) or computed tomography (CT) are not recommended as a routine for children but only in specific cases presenting with pneumonia and/or acute respiratory distress syndrome (ARDS). Parenchymal abnormalities with peripheral consolidations on CXR have been reported in a small case series from Korea [14]. Ground glass opacities (32\%), local patchy shadows (18\%) and bilateral patchy shadows $(12 \%)$ on CT chest were the common findings in children [7]. Bilateral pneumonia (75\%), unilateral pneumonia $(25 \%)$ and multiple mottling and ground-glass opacity (14\%) were reported based on CXR and CT findings from adult patients in Wuhan, China [15].

Laboratory markers of organ dysfunction: Elevation of transaminases is seen in $12-14 \%$ and d-Dimer in $14 \%$ cases [7].

\section{PREPAREDNESS AND ADMINISTRATIVE CONCERNS FOR ICU}

A phased and tiered plan for ICU during the pandemic needs to be made based on the assessment of healthcare burden and resource utilization [13,22,23].

Intensive care units: Create cohort intensive care units where critically ill confirmed COVID-19 patients will be managed. This would be a different area from where other PICU patients are being managed in order to reduce transmission within the hospital. In addition, a separate area should be developed where suspected COVID-19 patients will be managed. With increasing burden of patients, general beds may have to be converted to ICU beds and provided with suitable infrastructure. Predictive models based on local epidemic need to be developed for expected number of patients as well as need of equipment.

Setting up of isolation rooms : Negative pressure isolation is the standard recommendation for management of a suspected or proven COVID-19 patient. However, in case of non-availability of these rooms, use single rooms with separate air outlet/exhaust, preferably on the higher floor of the building. These rooms should be equipped with resuscitation trolley, essential drugs, multipara monitor and ventilator. Positive pressure rooms 
like operation theatres are not suitable for airway management as aerosol generation is higher.

Reducing the ICU burden: All elective non-urgent admissions and surgeries need to be halted during the outbreak in order to rationalize resource-utilization, and ensure adequate back-up to handle the crisis.

Re-allocation of staff: During the crisis, there may be acute shortage of critical care specialists and nursing staff. It is essential to identify staff from respiratory medicine, infectious disease and other units who may be trained in infection control, personal protective equipment (PPE) use and management of critically ill patients.

Rotation of staff and reserve for back-up: Adequate reserve of healthcare providers needs to be ensured as a back-up in case of emergencies or healthcare professionals falling sick. The team members should be working on rotation (in a shift of 4-7 days) with adequate rest in between.

Training of all staff: All those who are likely to come in close contact with the patient or are handling equipment, surroundings, and waste management should receive training regarding infection control including correct technique of donning and doffing of PPE and disinfection of surfaces and equipments. Proper training and a written plan (Standard Operating Procedure) should be there for waste disposal.

Rational use of PPE: In view of current global shortage, WHO has formulated guidelines for the rational use of PPE. This includes co-ordination of PPE supply chain management mechanism, appropriate PPE use based on indication, minimizing the need of PPE by bundling activities, using physical barriers and telemedicine where appropriate, and restricting visitors [24].

\section{MANAGEMENT IN RESOURCE-LIMITED SETTINGS}

\section{Triage andTransport}

A dedicated area for screening and triaging of patients with suspected COVID-19 is essential. Once the patient fits to the case definition and requires admission, unnecessary movement must be avoided and minimum staff should accompany the patient. Ensure that the patient (if self-breathing) and the accompanying persons should be on a 3-ply surgical mask.

\section{ICU Management}

Severe and critical cases need ICU care for monitoring, ventilation and organ support therapy.
Severe acute respiratory illness (SARI): SARI is defined by the presence of cough and fast breathing plus at least one of the following [25]:(i) Oxygen saturation $\left(\mathrm{SpO}_{2}\right)$ $<90 \%$, (ii) severe chest indrawing and grunting, and (iii) altered mental status.

SARI is the most common indication for ICU transfer and most guidelines are similar to management of any viral pneumonia with ARDS with an emphasis on minimizing risk of transmission to others, especially healthcare workers [26,27]. The details on the management of SARI are given in Part II of this write-up and Table I.

Septic shock: Management of septic shock in COVID is not very different from the routine. However, the Surviving Sepsis Campaign (SSC) guidelines for COVID-19 recommend conservative fluid strategy, avoiding colloids as resuscitation fluid, and to use low dose steroids in catecholamine refractory shock [28]. In children, epinephrine is the first vasoactive of choice for septic shock.

Co-infections: Co-infections like secondary bacterial pneumonia are common, especially in children (50\%) and addition of broad spectrum antibiotic to cover gram positive, gram negative, and staphylococcal infection is recommended [29].

Myocarditis: Cardiogenic shock with elevations in hypersensitive Tropnonin-I have been seen in $12 \%$ of patients. Management includes inodilators like milrinone, diuretics, immunomodulators (methylprednisolone and IVIG) and circulatory support with ECMO (extracorporeal membrane oxygenation) have also been used in a few cases $[30,31]$.

Acute kidney injury : This has been reported in 7\% and renal replacement therapy may be necessary [32].

Supportive care: This includes conservative fluid management, nutrition, appropriate sedo-analgesia, and prevention and treatment of healthcare associated infections.

\section{Specific Therapy}

Although no definitive therapy till date has proven benefit for SARS-CoV2, antiviral drugs like Remdesivir, Lopinavir/Ritonavir are being used in over $50 \%$ of the critically ill adults based on in vitro viral inhibition and recovery in SARS and MERS but there is no strong evidence [33-36]. Chloroquine has been found to increase endosomal $\mathrm{pH}$ and hinder virus cell fusion and also interfere with ACE2, a receptor for binding of SARS-CoV2 [37]. A combination of hydroxychloroquine and azithromycin showed reduction in viral load [38]. 
Table I Treatment Based on Severity of Disease in Proven Coronavirus Disease-19 (COVID-19)

\begin{tabular}{|c|c|c|c|}
\hline $\begin{array}{l}\text { Symptomatic } \\
\text { proven case }\end{array}$ & Admit in & Treatment & Discharge \\
\hline Mild & $\begin{array}{l}\text { Designated COVID } \\
\text { isolation room }\end{array}$ & Symptomatic treatment & $\begin{array}{l}\text { Discharge if } 72 \mathrm{~h} \text { afebrile or } 7 \mathrm{~d} \text { after symptom } \\
\text { onset and two samples negative } 24 \mathrm{~h} \text { apart } \\
\text { followed by home quarantine for total } 14 \mathrm{~d}\end{array}$ \\
\hline Moderate & $\begin{array}{l}\text { Designated COVID } \\
\text { isolation room }\end{array}$ & $\begin{array}{l}\text { Supportive care, oxygen } \\
\text { Oseltamivir }\end{array}$ & $\begin{array}{l}\text { Clinical improvement and two negative } \\
\text { nCoV PCR tests } 24 \mathrm{~h} \text { apart }\end{array}$ \\
\hline Severe & COVID ICU & $\begin{array}{l}\text { Provide nasal prong oxygen } \\
\text { Escalate to invasive ventilation } \\
\text { if worsening } \\
\text { Avoid HFNC/NIV } \\
\text { Oseltamivir Ritonavir/Lopinavir } \\
\text { OR Hydroxychloroquine } \\
\text { Supportive care }\end{array}$ & $\begin{array}{l}\text { Clinical improvement and two negative } \\
\text { nCoV PCR tests } 24 \mathrm{~h} \text { apart }\end{array}$ \\
\hline Critical & COVID ICU & $\begin{array}{l}\text { In addition to the above: } \\
\text { Intubate based on clinical/blood } \\
\text { gas/radiological features } \\
\text { Use all airborne precautions } \\
\text { Ventilation ARDS protocol } \\
\text { Other organ support } \\
\text { Once improving, wean from } \\
\text { ventilator and extubate as per } \\
\text { protocol }\end{array}$ & $\begin{array}{l}\text { Clinical improvement and two negative } \\
\text { nCoV PCR tests } 24 \mathrm{~h} \text { apart }\end{array}$ \\
\hline
\end{tabular}

HFNC: High-flow nasal cannula, NIV: Non-invasive ventilation, ICU: intensive care unit,ARDS: Acute respiratory distress syndrome.

Interferons, IVIG, and convalescent plasma from recovered SARS patients are other tested treatment options [39]. Vaccination for RNA viruses (measles, influenza, polio) has shown higher titers of neutralizing antibodies against SARS-CoV [40] (Table II). Based on the current experience, we may use broad spectrum antibiotics, oseltamivir, protease inhibitors, hydroxychloroquine and azithromycin. Lopinavir/Ritonavir along with Chloroquine should be avoided in combination.

\section{Course and Recovery}

In adult patients with COVID-19 pneumonia, onset of symptoms to respiratory failure takes an average of 7 days with peak severity at 10 days. Signs of improvement starts occurring by day 14 . However, at the time of reporting of most studies, many patients were still admitted and their course needs to be followed to know the exact prognosis [40].

\section{INFECTION PREVENTION AND CONTROL}

In the intensive care setting, disinfection of high-touch surfaces like monitors, ventilator screen, other equipment, resuscitation trolleys etc are essential and need to be carried out every 4 hours.

Surface decontamination: Alcohol (e.g. isopropyl 70\% or ethyl alcohol $70 \%$ ) can be used to wipe down surfaces where the use of bleach is not suitable for e.g. Mobiles, laptops, keys, pens etc.

Disinfection: Freshly prepared1\% sodium hypochlorite should be used as a disinfectant for cleaning and disinfection with at least 10 minute contact period.

Aerosol: Ensure room disinfection within 20 minutes of any procedure generating aerosol.

Social distancing: Maintain at least 1 meter distance unless required for examination or procedure.

Contact and droplet precautions: minimize direct contact, ensure hand hygiene, and cough etiquette.

\section{Healthcare Worker (HCW) Risks}

Apart from risks related to droplet spread and from contaminated surfaces, ICU professionals face the challenge of acquiring infection during aerosol generating procedures (see table in Part II). HCW should wear a medical mask and gown when entering a room where patients with suspected or confirmed COVID-19 are admitted and use full personal protective equipment (PPE), which includes N95 mask, goggles or face shield, cap, full sleeve gown and shoe cover, when performing aerosol-generating procedures [41]. The entire PPE is 


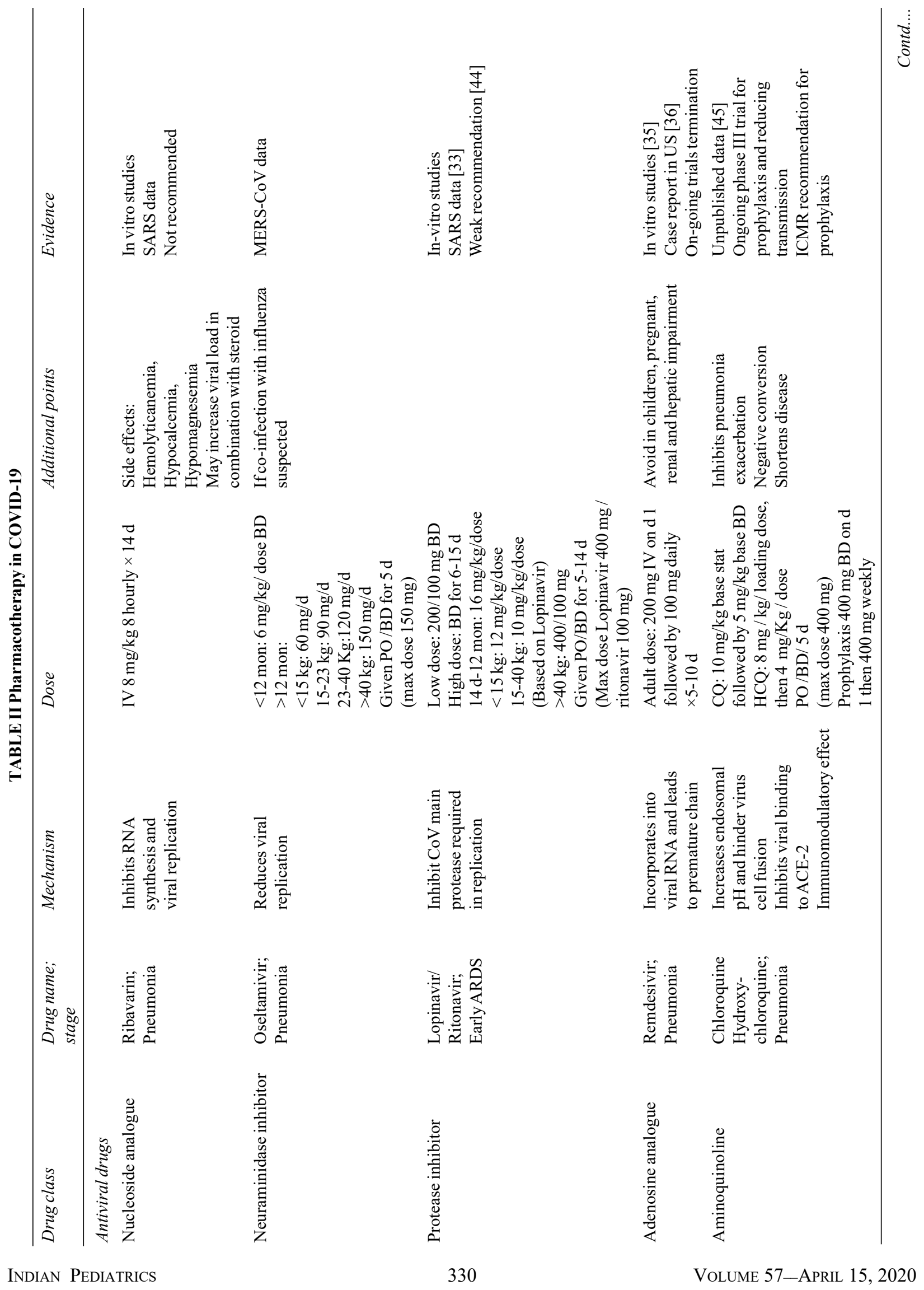




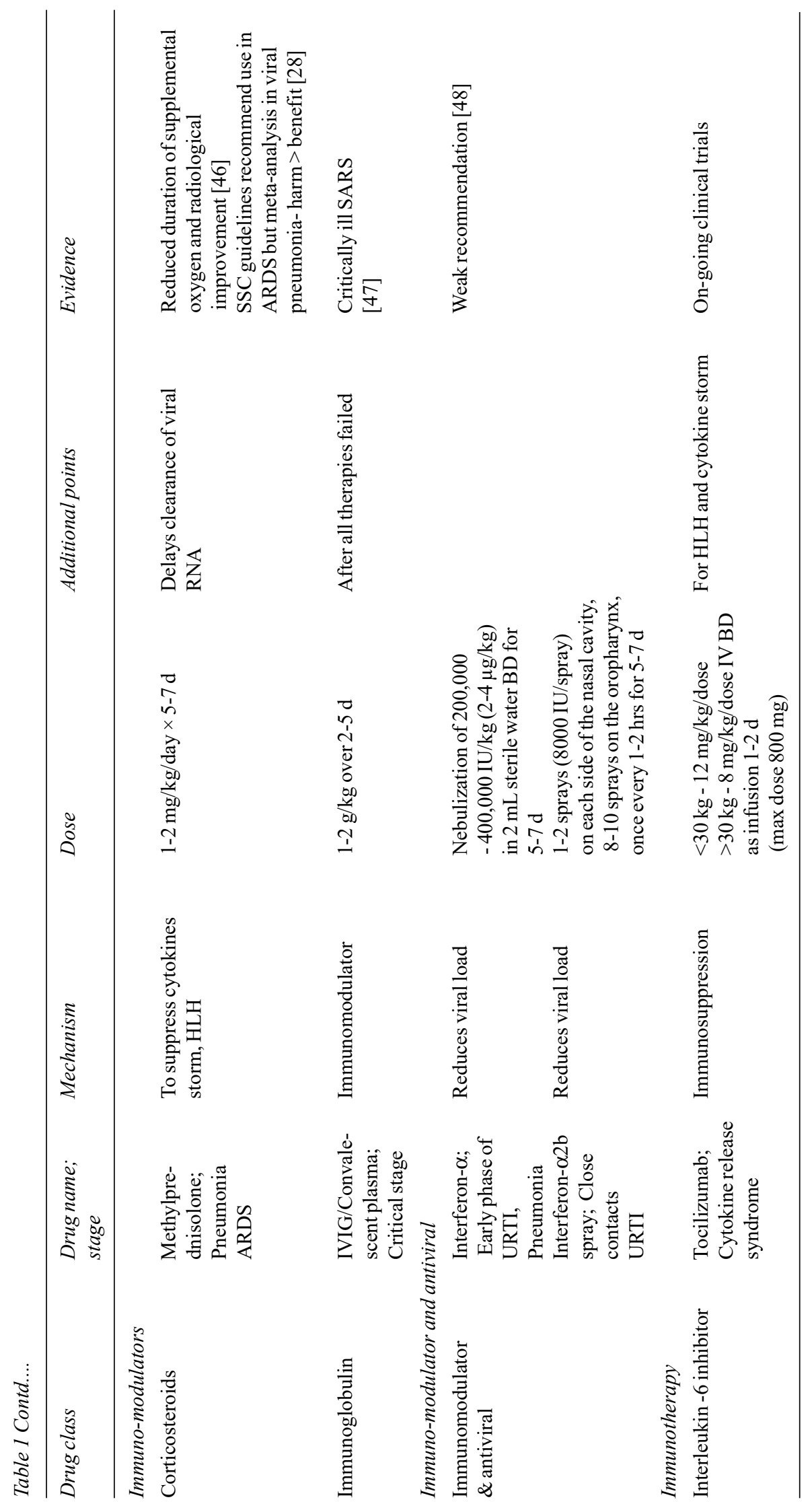

INDIAN Pediatrics 
recommended to be used for 4-6 hours and changed earlier if there is any soiling. Team should not include staff vulnerable to infection like immunocompromised person, pregnant ladies, age $>60$ years or those with comorbidities. In the event of exposure and manifestation of infection, management as per guidelines as well as psychosocial support needs to be ensured. Adequate communication, education and adherence to strict personal protection can minimize the risk of transmission to HCW [26]. ICMR recommends prophylactic use of hydroxychloroquine $400 \mathrm{mg}$ twice a day on day 1 , followed by $400 \mathrm{mg}$ once weekly for next 7 weeksfor HCW managing suspected or confirmed COVID-19 patients [42].

\section{Special Considerations for Resuscitation}

It is important to minimize the number of people inside the room during high aerosol generating events like cardiopulmonary resuscitation. One airway specialist, one nurse/doctor for chest compression and one nurse for medication are essential. Other assistants may remain outside the room and may enter only if necessary after donning full PPE. Hand bagging needs to be avoided. During any disconnection from ventilator, endotracheal (ET) tube needs to be clamped and/or viral filter attached to the ET tube. In case re-intubation is required, follow the standard procedure described (see Part II in this issue).

\section{CONCLUSION}

The COVID-19 pandemic caused by 2019-nCOV has become a serious concern for mankind all over the world. It has challenged and overwhelmed the existing intensive care facilities globally. SARI is the most common indication for intensive care management and is associated with high mortality. The disease so far appears to be less common in children and seems to have a milder course. Preparation for handling crisis during this outbreak is essential for early identification, stratification and management of cases. Prevention by ensuring strict infection control practices minimizes transmission to other patients and healthcare workers, especially in intensive care units.

Contributors: NR, KN, AB, SKA: substantial contribution to the conception and design of the work (ii) drafting the work (iii) final approval of the version to be published (iv) agreement to be accountable for all aspects of the work in ensuring that questions related to the accuracy or integrity of any part of the work are appropriately investigated and resolved; GVB, MS, RL, DG, MJ: substantial contributions to the acquisition and interpretation of data for the work (ii) revising it critically for important intellectual content (iii) Final approval of the version to be published (iv) Agreement to be accountable for all aspects of the work in ensuring that questions related to the accuracy or integrity of any part of the work are appropriately investigated and resolved.

Funding: None; Competing interests: None stated.

\section{REFERENCES}

1. Wu Z, McGoogan JM. Characteristics of and important lessons from the coronavirus disease 2019 (covid-19) outbreak in China: Summary of a report of 72/ 314 cases from the Chinese center for disease control and prevention [published online ahead of print]. JAMA. 2020;10.1001/ jama.2020.2648. Available from: https://jamanetwork.com/ journals/jama/fullarticle/2762130. Accessed March 25, 2020.

2. Shen K, Yang Y, Wang T, Zhao D, Jiang Y, Jin R, et al. Diagnosis, treatment, and prevention of 2019 novel coronavirus infection in children: experts' consensus statement. World J Pediatr (2020). https://doi.org/10.1007/ s12519-020-00343-7. Accessed March 25, 2020.

3. Coronavirus disease 2019 [Internet]. [cited 2020 Mar 26]. Available from: https://www.who.int/emergencies/diseases/ novel-coronavirus-2019.

4. de Wilde AH, Snijder EJ, Kikkert M, van Hemert MJ. Host factors in coronavirus replication. Curr Topic Microbiol Immunol. 2018;419:1-42.

5. Paules CI, Marston HD, Fauci AS. Coronavirus infectionsMore than just the common cold. JAMA. 2020;323:707-8.

6. Li Q, Guan X, Wu P, Wang X, Zhou L, Tong Y, et al. Early transmission dynamics in Wuhan, China, of novel coronavirus-infected pneumonia. N Engl J Med. 2020; 382:1199-207.

7. Lu X, Zhang L, Du H, Zhang J, Li Y, Qu J, et al. SARSCoV-2 Infection in Children. New England J Med. 2020. Available from: https://www.nejm.org/doi/ full/10.1056/ NEJMc2005073. Accessed March 24, 2020.

8. Lee P-I, Hu Y-L, Chen P-Y, Huang Y-C, Hsueh P-R. Are children less susceptible to COVID-19? JMicrobiol Immunol Infect. 2020. Available from: https://www.sciencedirect.com/ science/article/pii/S1684118220300396?via\%3Dihub. Accessed March 24, 2020.

9. Li W, Moore MJ, Vasilieva N Sui J, Wong SK, Berne MA, et al. Angiotensin-converting enzyme 2 is a functional receptor for the SARS coronavirus. Nature. 2003;426:450-54.

10. Mahase E. Coronavirus: covid-19 has killed more people than SARS and MERS combined, despite lower case fatality rate. BMJ. 2020;368:m641. Available from https:// www.bmj.com/content/368/bmj.m641. Accessed March 29, 2020.

11. Onder G, Rezza G, Brusaferro S. Case-fatality rate and characteristics of patients dying in relation to COVID-19 in Italy. JAMA. Published online March 23, 2020. doi:10.1001/jama.2020.4683. Accessed March 29, 2020.

12. Yang X, Yu Y, Xu J, Shu H, Xia J, Liu H, et al. Clinical course and outcomes of critically ill patients with SARSCoV-2 pneumonia in Wuhan, China: A single-centered, retrospective, observational study. Lancet Respiratory Medicine. 2020. Available from: https://doi.org/10.1016/ S2213-2600(20)30079-5. Accessed March 29, 2020 
13. Grasselli G, Pesenti A, Cecconi M. Critical care utilization for the COVID-19 outbreak in Lombardy, Italy: Early experience and forecast during an emergency response. JAMA. Published online March 13, 2020. doi:10.1001/ jama.2020.4031. Accessed March 29, 2020

14. Yoon SH, Lee KH, Kim JY, Lee YK, Ko H, Kim KH, et al. Chest radiographic and CT findings of the 2019 Novel Coronavirus Disease (COVID-19): Analysis of nine patients treated in Korea. Korean J Radiol. 2020;21:494-500.

15. Chen N, Zhou M, Dong X, Qu J, Gong F, Han Y, et al. Epidemiological and clinical characteristics of 99 cases of 2019 novel coronavirus pneumonia in Wuhan, China: A descriptive study. Lancet. 2020;395:507-13.

16. Available from: https://www.who.int/docs/default-source/ coronaviruse/situation-reports-48. Accessed March 29, 2020

17. Dong Y, Mo X, Hu Y, Qi X, Jiang F, Jiang Z, et al. Epidemiological characteristics of 2143 pediatric patients with 2019 coronavirus disease in China. Pediatrics. 2020; doi: 10.1542/peds.2020-0702. Accessed March 29, 2020

18. Indian Council of Medical Research. Revised Strategy of COVID19 testing in India (Version 3, dated 20/03/2020). Available from: https://icmr.nic.in/sites/default/files/ upload_documents/2020-03-20_covid19_test_v3.pdf. Accessed March 29, 2020

19. World Health Organization. (2020). Laboratory testing for coronavirus disease 2019 (COVID-19) in suspected human cases: Interim guidance, 2 March 2020. World Health Organization. Available from: https://apps.who.int/iris/ handle/10665/331329. Accessed March 30, 2020.

20. Xpert ${ }^{\circledR}$ Xpress SARS-CoV-2. Instructions for Use. Cepheid, California, USA; 2020. Available from: https:// www.fdagov/media/136314/download. Accessed March 30,2020

21. Indian Council of Medical Research. Press Release on "Fast Track Approval for Indian COVID-19 Testing Kits for Commercial Use." Available from: https:// www.icmr.nic.in/content/press-release-fast-trackapproval-indian-covid-19-testing-kits-commercial-use. Accessed March 30, 2020

22. The Australian and New Zealand Intensive Care Society (ANZICS). COVID-19 Guidelines Version 1. Available from: http://cec.health.nsw.gov.au/_data/assets/pdf_file/ 0004/572512/ ANZICS-COVID-19-Guidelines-Version1.pdf. Accessed March 30, 2020.

23. Xie J, Tong Z, Guan X, Du B, Qui H, Slutsky AS. Critical care crisis and some recommendations during the COVID19 epidemic in China. Intensive Care Med. 2020. Available from: https://doi.org/10.1007/s00134-020-05979-7. Accessed March 29, 2020.

24. Available from: https://apps.who.int/iris/bitstream/ handle/10665/331215/WHO-2019-nCov-IPCPPE_use2020.1-eng.pdf. Accessed March 29, 2020.

25. Clinical management of severe acute respiratory infection (SARI) when COVID-19 disease is suspected Interim guidance. WHO/2019-nCoV/clinical/2020.4. Accessed March 29, 2020.

26. Murthy S, Gomersall CD, Fowler RA. Care for Critically Ill Patients With COVID-19. JAMA. Published online March
11, 2020. doi:10.1001/jama.2020.3633. Accessed March 29, 2020.

27. Brewster DJ, Chrimes NC, Do TBT, Fraser K, Groombridge CJ, Higgs A, et al. Consensus statement: Safe Airway Society principles of airway management and tracheal intubation specific to the COVID-19 adult patient group. Med J Aust. March 16, 2020. Accessed March 29, 2020

28. Alhazzani W, Møller MH, Arabi YM, Loeb M, Gong MN, Fan E, et al. Surviving Sepsis Campaign: Guidelines on the Management of Critically Ill Adults with Coronavirus Disease 2019 (COVID-19). Intensive Care Med. https:// doi.org/10.1007/s00134-020-06022-5. Accessed March 29, 2020

29. Xia W, Shao J, Guo Y, Peng X, Li Z, Hu D. Clinical and CT features in pediatric patients with COVID 19 infection: Different points from adults. doi.org/10.1002/ppul.24718. Accessed March 29, 2020

30. Hongde $\mathrm{Hu}$, Fenglian $\mathrm{Ma}$, Xin Wei, Yuan Fang. Coronavirus fulminant myocarditis saved with glucocorticoid and human immunoglobulin, Eur Heart J. 2020; ehaa190. https:// academic.oup.com/eurheartj/ advance-article/doi/10.1093/eurheartj/ehaa190/ 5807656.Accessed March 29, 2020

31. Zeng J, Liu Y, Yuan J, Wang F, Wu W, Li J, et al. First case of COVID-19 infection with fulminant myocarditis complication: Case report and insights [Pre-print]. Preprints 2020, 2020030180. Available from https:// www.preprints.org/manuscript/202003.0180/v1. Accessed March 29, 2020.

32. Huang C, Wang Y, Li X, Ren L, Zhao J, Hu Y, et al. Clinical features of patients infected with 2019 novel coronavirus in Wuhan, China. Lancet. 2020;395:497-506.

33. Chan KS, Lai ST, Chu CM, Tsui E, Tam CY, Wong MML, et al. Treatment of severe acute respiratory syndrome with lopinavir/ritonavir: A multicentre retrospective matched cohort study. Hong Kong Med J. 2003;9:399-406.

34. Cao B, Wang Y, Wen D, Liu W, Wang J, Fan G, et al. A trial of lopinavir-ritonavir in adults hospitalized with severe Covid-19. New Engl J Med. 2020 [Online early]. Available from: https://www.nejm.org/doi/full/10.1056/ NEJMoa2001282.Accessed March 29, 2020

35. Wang M, Cao R, Zhang L, Yang X, Liu J, Xu M, et al. Remdesivir and chloroquine effectively inhibit the recently emerged novel coronavirus (2019-nCoV) in vitro. Cell Res 2020;30:269-71.

36. Holshue ML, DeBolt C, Lindquist S, Lofy KH, Wiesman J, Bruce H, et al. First case of 2019 novel coronavirus in the United States. N Engl J Med. 2020;382:929-36.

37. Vincent M, Bergeron E, Benjannet S, Erickson B, Rollin P, Ksiazek T, et al. Chloroquine is a potent inhibitor of SARS coronavirus infection and spread. Virol J. 2005;2:69.

38. Gautret P, Lagiera J, Parolaa P, Hoanga V, Meddeba L, Mailhe $\mathrm{M}$, et al. Hydroxychloroquine and azithromycin as a treatment of COVID 19: Results of an open label non randomized clinical trial. Int J Antimicrob Agent. 2020 [Online early] Available from: http://www.sciencedirect.com/ science/article/pii/S0924857920300996. Accessed March 29, 2020. 
39. Wang BX, Fish EN. Global virus outbreaks: interferons as 1st responders. SeminImmunol. 2019;43:101300. Available from http://www.sciencedirect.com/science/ article/pii/S1044532319300065. Accessed March 29, 2020.

40. Zhang L, Liu Y. Potential interventions for novel coronavirus in China: A systematic review. J Med Virol. 2020;92:479-90.

41. Pan F, Ye T, Sun P, Gui S, Liang B, Li L, et al. Time course of lung changes on chest ct during recovery from 2019 novel coronavirus (COVID-19) pneumonia. Available from:https://pubs.rsna.org/doi/10.1148/radiol. 2020200370. Accessed March 29, 2020.

42. World Health Organization. Advice on the use of masks in the community, during home care and in healthcare settings in the context of the novel coronavirus (COVID-19) outbreak [internet]. Available from: https://www.who.int/ publications-detail/advice-on-the-use-of-masks-in-thecommunity-during-home-care-and-in-healthcare-settingsin-the-context-of-the-novel-coronavirus-(2019-ncov)outbreak. Accessed March 25, 2020.

43. Indian Council of Medical research. Recommendation for empiric use of hydroxy-chloroquine for prophylaxis of SARS-CoV-2 infection [internet]. Available from: https:// icmr.nic.in/sites/default/files/upload_documents/ HCQ_Recommendation_22March_final_MM.pdf.Accessed March 25, 2020.
44. Wang XF, Yuan J, Zheng YJ, Chen J, Bao YM, Wang YR, et al. Clinical and epidemiological characteristics of 34 children with 2019 novel coronavirus infection in Shenzhen [English abstract]. Zhonghua Er Ke Za Zhi. 2020;58:E008. [Retracted].

45. Gao J, Tian Z, Yang X. Breakthrough: Chloroquine phosphate has shown apparent efficacy in treatment of COVID-19 associated pneumonia in clinical studies. Biosci Trends. 2020;14:72-3.

46. Wang Y, Jiang W, He Q, Wang C, Wang B, Zhou P, et al. Early, low-dose and short-term application of corticosteroid treatment in patients with severe COVID-19 pneumonia: single-center experience from Wuhan, China [pre-print]. Available from: https://doi.org/10.110/ 2020.03.06.20032342. Accessed March 29, 2020.

47. Chen L, Xiong J, Bao L, Shi Y. Convalescent plasma as a potential therapy for COVID-19[Published online ahead of print]. Lancet Infect Dis. 2020;S1473-3099(20)30141-9. Available from: https://doi.org/10.1016/S1473-3099(20) 30141-9.Accessed March 29, 2020.

48. Jin Y, Cai L, Cheng Z, Cheng H, Deng T, Fan Y, et al. A rapid advice guideline for the diagnosis and treatment of 2019 novel coronavirus (2019-nCoV) infected pneumonia (standard version). Military Med Res. 2020;7: 4. Available from: https://mmrjournal. biomedcentral.com/articles/ 10.1186/s40779-020-0233-6. Accessed March 29, 2020. 